\title{
Structure and reactivity of ceria-zirconia catalysts for bromine and chlorine production via the oxidation of hydrogen halides
}

Maximilian Moser ${ }^{a}$, Gianvito Viléa , Sara Colussi ${ }^{b}$, Frank Krumeich ${ }^{c}$, Detre Teschner ${ }^{d}$, László Szentmiklósi ${ }^{\mathrm{e}}$, Alessandro Trovarelli*, ${ }^{*, \mathrm{~b}}$, and Javier Pérez-Ramírez ${ }^{\star, a}$

a Institute for Chemical and Bioengineering, Department of Chemistry and Applied Biosciences, ETH Zurich, Vladimir-Prelog-Weg 1, 8093 Zurich, Switzerland

${ }^{b}$ Department of Chemistry, Physics, and Environment, University of Udine, Via del Cotonificio 108, 33100 Udine, Italy

${ }^{c}$ Laboratory of Inorganic Chemistry, Department of Chemistry and Applied Biosciences, ETH Zurich, Vladimir-Prelog-Weg 1, 8093 Zurich, Switzerland

${ }^{d}$ Fritz-Haber-Institute of the Max Planck Society, Faradayweg 4-6, 14195 Berlin, Germany

e Centre for Energy Research, Hungarian Academy of Sciences, Konkoly-Thege Miklós street 29-33, 1121 Budapest, Hungary

* Corresponding authors. E-mails: trovarelli@uniud.it (A.T.); jpr@chem.ethz.ch (J.P.-R.) 


\section{Abstract}

The impact of zirconia on the activity and stability of ceria has been investigated in the gasphase oxidation of $\mathrm{HBr}$ and $\mathrm{HCl}$ to the corresponding halogens. Homogeneous and nonhomogeneous ceria-zirconia catalysts with a $\mathrm{Ce}: \mathrm{Zr}$ ratio of $75: 25$ were prepared and characterized by X-ray diffraction, temperature-programmed reduction in hydrogen, transmission electron microscopy, and X-ray photoelectron spectroscopy. Catalytic tests demonstrated the $\mathrm{ZrO}_{2}$ promotes the activity of $\mathrm{CeO}_{2}$ independently of the metal homogeneity in the mixed oxide. Upon cycling of the temperature and feed composition up and down, no differences with respect to chlorine formation was observed. On the other hand, a hysteresis of the reaction rate was measured in $\mathrm{HBr}$ oxidation, which was more pronounced over the nonhomogeneous mixed oxide due to the higher extent of bromination. A moderate degree of bromination was attained in the homogeneous mixed oxide, leading to an improved long-term stability. The impact of phase homogeneity on the halogenation properties of the catalysts, and thus on the lifetime, was further rationalized by the determination of the halogen uptake by operando prompt-gamma activation analysis. While the chlorine uptake under different reaction conditions was comparable over both materials, the bromine uptake on the non-homogeneous sample was up to $50 \%$ higher compared to the homogeneous counterpart. This indicates not only that the catalysts are more prone to bromination than chlorination, but also that their robustness depends on the intermixing of the $\mathrm{Ce}$ and $\mathrm{Zr}$ phases, suggesting that the mixed oxides are more stable than supported ceria catalysts. The degree of halogenation of the homogeneous ceria-zirconia catalysts can be controlled by tuning their $\mathrm{Ce}: \mathrm{Zr}$ ratio, minimizing the halogen uptake at a $\mathrm{Zr}$ content in the range of $70-90 \mathrm{~mol} . \%$.

Keywords: hydrogen halide oxidation; bromine; chlorine; $\mathrm{CeO}_{2}-\mathrm{ZrO}_{2}$; mixed oxide; promptgamma activation analysis. 


\section{Introduction}

Ceria $\left(\mathrm{CeO}_{2}\right)$ is a key ingredient of many heterogeneous catalysts for a variety of reactions [1-6], including the oxidation of $\mathrm{HCl}$, a key step to recover $\mathrm{Cl}_{2}$ in the polyurethane and polycarbonate industries [7-9]. In this reaction, the success of $\mathrm{CeO}_{2}$ can be attributed to its unique structural and electronic properties associated with the ability to switch easily between the $\mathrm{Ce}^{4+}$ and $\mathrm{Ce}^{3+}$ oxidation states, forming and annihilating oxygen vacancies which function as active sites [10-15]. However, under oxygen-lean conditions, ceria tends to form chlorinated species at the surface and the bulk, which lead to the deactivation of the catalyst [9]. In an attempt to enhance the stability of $\mathrm{CeO}_{2}$, it has been shown that the use of $\mathrm{ZrO}_{2}$ as a carrier could significantly promote the performance of ceria compared to $\mathrm{Al}_{2} \mathrm{O}_{3}$ and $\mathrm{TiO}_{2}$, due to the improved redox properties of the $\mathrm{CeO}_{2} / \mathrm{ZrO}_{2}$ catalyst [16]. The latter catalyst also exhibited lower chlorine uptake during reaction compared to $\mathrm{CeO}_{2} / \mathrm{Al}_{2} \mathrm{O}_{3}$, as shown by operando promptgamma activation analysis. This resulted in an increase of the stability of ceria, which was verified in a $700 \mathrm{~h}$ stability test over a technical $\mathrm{CeO}_{2} / \mathrm{ZrO}_{2}$ catalyst at pilot scale [16].

The successful demonstration of $\mathrm{CeO}_{2} / \mathrm{ZrO}_{2}$ triggered further investigations that focused on the effect of intermixing ceria and zirconia by doping strategies. In fact, the doping of $\mathrm{CeO}_{2}$ with iso- and aliovalent elements is an attractive methodology to lower the formation energy of oxygen vacancies $[13,17-20]$, as shown for the automotive three-way catalyst where the incorporation of $\mathrm{Zr}^{4+}$ into $\mathrm{CeO}_{2}$ with a $\mathrm{Ce}: \mathrm{Zr}$ ratio of $75: 25$ enhances its catalytic performance [21-23]. The incorporation of $20 \mathrm{~mol} . \%$ of $\mathrm{Zr}^{4+}$ into bulk ceria promotes the $\mathrm{HCl}$ oxidation activity in contrast to trivalent ions such as $\mathrm{La}^{3+}$ [24]. Theoretical calculations suggested that the balanced reduction between the formation energies of both oxygen and chlorine vacancies enhanced the activity [24]. These results were supported by studies on the structural stability of electrospun ceria-zirconia nanofibers, observing that the incorporation of at least $20 \mathrm{~mol} . \% \mathrm{ZrO}_{2}$ into $\mathrm{CeO}_{2}$ increases the stability against sintering and lowered the likelihood of bulk cerium chloride formation compared to pure ceria $[25,26]$. 
The developments in catalytic $\mathrm{HCl}$ oxidation additionally envisaged new studies on $\mathrm{HBr}$ oxidation, an attractive route to recover $\mathrm{Br}_{2}$ from bromine-mediated alkane functionalization processes [27]. Ceria has been reported as potential catalyst for this reaction besides $\mathrm{RuO}_{2}$ and $\mathrm{TiO}_{2}[28,29]$. However, apart from preliminary activity tests, no work has been dedicated to investigate the differences of ceria-catalyzed $\mathrm{HBr}$ and $\mathrm{HCl}$ oxidation, the role of an additional metal (such as $\mathrm{Zr}^{4+}$ ) on the performance of ceria, as well as the robustness of ceria-based systems for $\mathrm{HBr}$ oxidation.

Herein, we have studied the effect of the phase homogeneity and composition of ceriazirconia catalysts for $\mathrm{HBr}$ and $\mathrm{HCl}$ oxidation. The materials were prepared by co-precipitation and thermal decomposition and characterized by bulk and surface techniques to determine structural and chemical features. The activity and stability of the catalysts were evaluated in the gas-phase oxidation of $\mathrm{HBr}$ and $\mathrm{HCl}$ at different temperatures and oxygen partial pressures. Operando prompt-gamma activation analysis was essential as it enabled to determine and compare the bromine and chlorine uptake at different conditions over the homogeneous and non-homogeneous ceria-zirconia catalysts. Our results underscore the necessity to maximize the homogeneity of the ceria-zirconia mixed oxide and to individually optimize the $\mathrm{Ce}: \mathrm{Zr}$ ratio in order to obtain a stable and active catalytic system for $\mathrm{HBr}$ and $\mathrm{HCl}$ oxidation.

\section{Experimental}

\subsection{Catalyst preparation}

Ceria-zirconia mixed oxides with different $\mathrm{Ce}: \mathrm{Zr}$ ratios were synthesized by following two different preparation routes. The samples are coded as 'CZXX', where $C$ represents $C e, Z$ represents $Z r$, and XX indicates the Ce content (0-100 mol.\%) in the mixed oxide (see Table 1). Homogeneous mixed oxides (coded with the suffix '-h') were prepared by co-precipitation of the precursor salts in the presence of $\mathrm{H}_{2} \mathrm{O}_{2}$. The addition of $\mathrm{H}_{2} \mathrm{O}_{2}$ during co-precipitation improves the morphological, redox, and thermal stability properties of the mixed oxide. $\mathrm{H}_{2} \mathrm{O}_{2}$, in fact, 
oxidizes the precursor $\mathrm{Ce}^{3+}$ species into the more easily hydrolysable $\mathrm{Ce}^{4+}$ and forms cerium hydroperoxide complexes. This disrupts the formation of a compact $\mathrm{Ce}-\mathrm{O}-\mathrm{Ce}$ network during the crystallization process, favoring the formation of highly-dispersed nanocrystallites of cerium oxide $[30,31]$. The desired amount of cerium nitrate $\left(\mathrm{Ce}\left(\mathrm{NO}_{3}\right)_{2} \cdot 6 \mathrm{H}_{2} \mathrm{O}\right.$, Treibacher Industrie $\left.A G\right)$ was dissolved in deionized water and kept under stirring while the corresponding amount of aqueous zirconyl nitrate $\left(\mathrm{ZrO}\left(\mathrm{NO}_{3}\right)_{2}\right.$, Treibacher Industrie $\left.\mathrm{AG}, 0.4 \mathrm{M}\right)$ was added. Hydrogen peroxide $\left(\mathrm{H}_{2} \mathrm{O}_{2}\right.$, Aldrich, $\left.35 \%\right)$ was poured into the solution to obtain a molar $\mathrm{H}_{2} \mathrm{O}_{2}:(\mathrm{Ce}+\mathrm{Zr})$ ratio of 3 . The precipitation of the ceria-zirconia precursor was obtained by addition of aqueous ammonium hydroxide $\left(\mathrm{NH}_{4} \mathrm{OH}\right.$, Aldrich, 30\%) until a $\mathrm{pH}$ of 10.5 was reached. The slurry was stirred for $4 \mathrm{~h}$, washed with deionized water, and filtered. The precipitate was dried overnight at $373 \mathrm{~K}$ and calcined in an oven with circulating air at $773 \mathrm{~K}$ for $3 \mathrm{~h}$. The non-homogeneous mixed oxides (coded with the suffix '-nh') were prepared by thermal decomposition of the precursor salts. In this case, cerium and zirconyl nitrates were dissolved in deionized water and the obtained solution was heated in an oil bath kept at $423 \mathrm{~K}$ under magnetic stirring, until complete evaporation of the solvent and precipitation of the solid. The catalyst was filtered, washed, dried overnight at $373 \mathrm{~K}$, and calcined in an oven with circulating air at $773 \mathrm{~K}$ for $3 \mathrm{~h}$. Pure $\mathrm{CeO}_{2}$ and $\mathrm{ZrO}_{2}$ were obtained by precipitation of the corresponding precursors in the presence of $\mathrm{H}_{2} \mathrm{O}_{2}$, following the same preparation procedure of the homogeneous mixed oxides.

\subsection{Catalyst characterization}

The $\mathrm{Ce}$ and $\mathrm{Zr}$ content of the samples was determined by X-ray fluorescence (XRF) spectrometry, using an Orbis Micro-EDXRF analyzer equipped with a $35 \mathrm{kV} \mathrm{Rh}$ anode and a silicon drift detector. The $\mathrm{Br}$ and $\mathrm{Cl}$ content in the mixed catalysts were determined by elemental analysis in a LECO CHN 900 combustion furnace. X-ray diffraction (XRD) patterns were recorded on a Philips X'Pert diffractometer equipped with an X'Celerator detector, using Nifiltered $\mathrm{Cu} \mathrm{K} \alpha$ radiation $(\lambda=1.542 \AA$ ). Rietveld refinement was carried out by using the GSAS- 
EXPGUI software package [32]. X-ray photoelectron spectroscopy (XPS) was conducted in a Physical Electronics Instruments Quantum 2000 spectrometer using monochromatic Al K $\alpha$ radiation generated from an electron beam operated at $15 \mathrm{kV}$ and $32.3 \mathrm{~W}$. The spectra were collected under ultra-high vacuum conditions (residual pressure $=5 \times 10^{-8} \mathrm{~Pa}$ ) at a pass energy of $50 \mathrm{eV}$. For chemical identification, the spectra were referenced to $\mathrm{Zr} 3 d$ at $182.2 \mathrm{eV} . \mathrm{N}_{2}$ sorption at $77 \mathrm{~K}$ was measured in a Micromeritics TriStar II unit after evacuation of the samples at $423 \mathrm{~K}$ for $90 \mathrm{~min}$. Temperature-programmed reduction in hydrogen $\left(\mathrm{H}_{2}-\mathrm{TPR}\right)$ was conducted in a Micromeritics Autochem 2920 unit equipped with a thermal conductivity detector. The catalyst (ca. $50 \mathrm{mg}$ ) was loaded into a U-shaped quartz micro-reactor and pretreated in air $\left(35 \mathrm{~cm}^{3} \mathrm{~min}^{-1}\right)$ at $623 \mathrm{~K}$ for $1 \mathrm{~h}$. The analysis was performed in $5 \mathrm{vol} . \% \mathrm{H}_{2} / \mathrm{N}_{2}\left(35 \mathrm{~cm}^{3} \mathrm{~min}^{-1}\right)$, ramping the temperature from 323 to $1273 \mathrm{~K}$ at $10 \mathrm{~K} \mathrm{~min}^{-1}$. Temperature-programmed desorption (TPD) of water and bromine was performed in the same setup, using a Balzers Omnistar QMS mass spectrometer for the chemical analysis of the gases. The catalyst (ca. $50 \mathrm{mg}$ ) was loaded into a U-shaped quartz micro-reactor and the analysis was conducted in air $\left(35 \mathrm{~cm}^{3} \mathrm{~min}^{-1}\right)$, ramping the temperature from 323 to $623 \mathrm{~K}$ at $10 \mathrm{~K} \mathrm{~min}^{-1}$. High-resolution transmission electron microscopy (HRTEM) was undertaken in a FEI Tecnai F30 microscope operated at $300 \mathrm{kV}$. Scanning transmission electron microscopy (STEM) analysis with elemental mapping using energy-dispersive X-ray spectroscopy (EDS) was conducted in a FEI Talos microscope operated at $200 \mathrm{kV}$. Prior to microscopic analyses, the solids were dispersed in ethanol; a few droplets of the suspension were poured onto a holey carbon-coated copper grid and dried completely.

\subsection{Catalyst testing}

The gas-phase oxidation of hydrogen halides was studied in a quartz continuous-flow fixedbed micro-reactor ( $8 \mathrm{~mm}$ internal diameter) at ambient pressure and in the temperature range of 
$450-750 \mathrm{~K}$. The reactor was loaded with $0.25 \mathrm{~g}$ of catalyst (particle size $=0.2-0.4 \mathrm{~mm}$ ). A total volumetric flow of $166 \mathrm{~cm}^{3} \mathrm{STP} \mathrm{min}^{-1}$ consisting of $10 \mathrm{vol} . \% \mathrm{HBr}$ or $\mathrm{HCl}$ (Air Liquide, anhydrous) and 7.5-90 vol. $\% \mathrm{O}_{2}$ (PanGas, purity 4.5 ) balanced in $\mathrm{N}_{2}$ (PanGas, purity 5.0 ) was continuously fed. After stabilizing the catalysts for $1 \mathrm{~h}$ under each condition, the halogen formation was quantified by iodometric titration using a Mettler Toledo G20 Compact Titrator. The iodometric titration is an off-line method to quantify $\mathrm{Br}_{2}$ and $\mathrm{Cl}_{2}\left(\mathrm{X}_{2}\right)$ contents in gas streams [33]. The gas at the reactor outlet pass through an impinger, equipped with a porous frit immersed into an aqueous $0.1 \mathrm{M} \mathrm{KI}$ (Axon Lab, 99\%) solution, and the following reaction takes place:

$\mathrm{X}_{2}+3 \mathrm{KI} \rightarrow \mathrm{I}_{3}^{-}+3 \mathrm{~K}^{+}+2 \mathrm{X}^{-}$. The formed triiodide ion is titrated using an aqueous $0.01 \mathrm{M} \mathrm{Na}_{2} \mathrm{~S}_{2} \mathrm{O}_{3}$ (Alfa Aesar, 99\%) solution, following the reaction: $\mathrm{I}_{3}{ }^{-}+2 \mathrm{Na}_{2} \mathrm{~S}_{2} \mathrm{O}_{3} \rightarrow 3 \mathrm{I}^{-}+4 \mathrm{Na}^{+}+\mathrm{S}_{4} \mathrm{O}_{6}{ }^{2-}$. The titration is performed at least twice to ensure reproducible results. The rate of halogen formation was expressed as mole of halogen produced per mole of total cerium in the solid and unit of time. The space-time yield was defined as gram of halogen produced per gram of catalyst and unit of time. After each experiment, the reactor was rapidly cooled down in $\mathrm{N}_{2}$ flow and the catalysts were collected for ex situ characterization.

\subsection{Operando PGAA}

The halogen uptake of the catalyst during $\mathrm{HBr}$ and $\mathrm{HCl}$ oxidation was determined by operando prompt-gamma activation analysis (PGAA) in the facilities of the Budapest Neutron Centre [34]. This technique has been previously applied to accurately determine the uptake of hydrogen on hydrogenation catalysts and the chlorine coverage on $\mathrm{HCl}$ oxidation catalysts under working conditions $[35,36]$. The catalytic experimental setup was identical with that described in Section 2.3, except for the reactor and the furnace, which were custom-designed to fit inside the neutron beam line. The catalyst testing was conducted according to the conditions described in Section 2.3 using $0.4 \mathrm{~g}$ of catalyst. The higher catalyst loading is chosen in order to improve the signal to noise ratio of the prompt-gamma signals and thus to reduce the data 
acquisition time. The cold neutrons were guided to the experimental station by curved supermirror neutron guides. The thermal-equivalent neutron flux at the PGAA sample position was $7.7 \times 10^{7} \mathrm{~cm}^{-2} \mathrm{~s}^{-1}$. A Compton-suppressed high-purity germanium (HPGe) crystal was used to detect the prompt-gamma photons. The halogen uptake was defined as the ratio of halogen (X) per total cerium and zirconium in the solid, i.e. $\mathrm{X}:(\mathrm{Ce}+\mathrm{Zr})$. The measured intensities include all molecules in the gas-phase and solid phase within the target volume. Thus, the gas-phase halogen signals $\left(\mathrm{HCl}, \mathrm{Cl}_{2}, \mathrm{HBr}, \mathrm{Br}_{2}\right)$ were subtracted, so that reported halogen uptake, $\mathrm{X}:(\mathrm{Ce}+\mathrm{Zr})$ corresponds only to the solid catalyst.

\section{Results and discussion}

\subsection{Characterization}

The main characteristics of the as-prepared homogeneous and non-homogeneous samples are summarized in Table 1 and 2, and compared with those of $\mathrm{CeO}_{2}$ and $\mathrm{ZrO}_{2}$. Elemental $\mathrm{Ce}: \mathrm{Zr}$ analysis by XRF verifies the nominal composition of the samples. For the homogeneous CZ75 sample, there is a clear correspondence between the bulk and surface $\mathrm{Ce}:(\mathrm{Ce}+\mathrm{Zr})$ ratios, indicating the surface homogeneity of the $\mathrm{Ce}$ and $\mathrm{Zr}$ phases. On the other hand, for the nonhomogeneous CZ75 catalyst, the surface values are much higher than the nominal ones, indicating surface enrichment of Ce. Structural heterogeneities were detected by EDS and XRD over the non-homogeneous CZ75-nh. This material, in fact, crystallizes in a cubic $\mathrm{CeO}_{2}$-rich phase $(a=5.4031(4) \AA)$ with segregation of tetragonal $\mathrm{ZrO}_{2}$ (Fig. 1 and Table 2). This is nicely depicted by the micrographs in Fig. 2, showing the inhomogeneity of the ceria and zirconia phases. On the other hand, CZ75-h has similar surface and bulk compositions. Compared to pure ceria (average crystallite size $=13 \mathrm{~nm}$ ), smaller crystallites are obtained in the homogeneous Zr-containing samples ( $6 \mathrm{~nm}$ for CZ75-h, and $5 \mathrm{~nm}$ for CZ50-h), in line with the higher total surface area of the mixed oxides, which reaches values around $80 \mathrm{~m}^{2} \mathrm{~g}^{-1}$ over 
CZ50-h. The formation of Ce-Zr mixed oxides in CZ75-h, CZ50-h, and CZ10-h is verified by the characteristic shift of the XRD peak position toward higher angles (Fig. 1 and Fig. S1a) and by the structural data in Table 2. Since several structures may be formed during the crystallization of the material, depending on the preparation condition and composition [37], Rietveld analysis of the diffraction profile has been carried out by opening up the fitting to different phases (cubic, tetragonal, and a mixture of the two). The analysis suggests that CZ75-h crystallizes in a cubic fluorite structure with a smaller cell parameter than ceria, in agreement with the introduction of the smaller $\mathrm{Zr}^{4+}$ ions in the lattice [24]. The value of the unit cell, $a=5.3540(4) \AA$, fits very well with values reported in the literature for similar compositions [38]. For CZ50-h, CZ10-h, and $\mathrm{CZO}$, the Rietveld analysis confirms a tetragonal structure with space group $\mathrm{P} 4_{2} / n m c$.

The reducibility of the samples was assessed by $\mathrm{H}_{2}$-TPR. Fig. $1 \mathrm{~b}$ and Fig. $\mathrm{S} 1 \mathrm{~b}$ show the qualitative profiles recorded over the catalysts, while Table 1 reports the quantitative $\mathrm{H}_{2}$ consumption up to $1273 \mathrm{~K}$. In fact, a contribution of the carbonates of ceria in form of $\mathrm{CO}_{2}$ could be excluded during the $\mathrm{H}_{2}$-TPR experiment (Fig. S2). The pure ceria sample presents a characteristic low-temperature peak at around $600-800 \mathrm{~K}$, assigned to the reduction of surface oxygen species, and a high-temperature peak at around $1073 \mathrm{~K}$, assigned to the reduction of the bulk of the $\mathrm{CeO}_{2}$ crystallites (Fig. S1b) [39]. A high temperature $\mathrm{H}_{2}$-uptake signal also characterizes the profile of the CZ75-nh sample, which shows three peaks at 623,823 , and $1023 \mathrm{~K}$ (Fig. 1). These can be attributed to the presence of segregated $\mathrm{CeO}_{2}$ or $\mathrm{CeO}_{2}$-rich phases. In contrast, the reduction takes place with a single, broad peak with maximum at approximately $853 \mathrm{~K}$ over CZ75-h (Figs. 1 and S1b), in agreement with the enhanced surface reducibility of homogeneous ceria-zirconia [20,21]. From a quantitative point of view, the homogeneous material is reduced to a higher extent compared with the non-homogeneous sample, as indicated in Table 1, in agreement with the enhanced reducibility of the homogeneous ceria-zirconia catalysts. 


\subsection{Oxidation of $\mathrm{HBr}$ and $\mathrm{HCl}$}

The performance of CZ75-h, CZ75-nh, and CZ100 was assessed in $\mathrm{HBr}$ and $\mathrm{HCl}$ oxidation at different temperatures (Fig. 3). The oxidation of $\mathrm{HBr}$ to $\mathrm{Br}_{2}$ occurs at ca. $200 \mathrm{~K}$ lower bed temperature compared to the $\mathrm{HCl}$ oxidation to $\mathrm{Cl}_{2}$, in line with recent studies on supported and bulk $\mathrm{CeO}_{2}$ [28]. In $\mathrm{HBr}$ oxidation, CZ75-h and CZ75-nh exhibit reaction rates of ca. 15 and $17 \mathrm{~mol} \mathrm{Br}_{2}$ mol Ce h$^{-1}$, respectively, which are about $33 \%$ higher than the rate of $\mathrm{CZ100}$ (11.8 $\left.\mathrm{mol} \mathrm{Br}_{2} \mathrm{~mol} \mathrm{Ce}^{-1}\right)$. The trend is the same in $\mathrm{HCl}$ oxidation, where both homogeneous and non-homogeneous catalysts yield rates of ca. $6 \mathrm{~mol} \mathrm{Cl}_{2} \mathrm{~mol} \mathrm{Ce} \mathrm{h}^{-1}$ at $723 \mathrm{~K}$ and the rate of CZ100 (3.2 $\left.\mathrm{mol} \mathrm{Cl}_{2} \mathrm{~mol} \mathrm{Ce} \mathrm{h}^{-1}\right)$ is $50 \%$ lower. Thus, $\mathrm{Zr}^{4+}$ seems to promote the activity of ceria, which could be related to the improved reducibility of the ceria-zirconia materials as evidenced by $\mathrm{H}_{2}$-TPR. However, during the temperature cycles no difference between the homogeneous and non-homogeneous samples is evident with respect to activity. The temperature cycles on all catalysts in $\mathrm{HCl}$ oxidation are stable. However, all three catalysts exhibit a strong hysteresis between the up- and downward cycles in $\mathrm{HBr}$ oxidation. At temperatures below $523 \mathrm{~K}$ the catalysts are merely active. After reaching $523 \mathrm{~K}$, the rate of bromine formation increases significantly within a temperature window of ca. $30 \mathrm{~K}$ (Fig. 3, blue circles). Upon reducing the temperature to $523 \mathrm{~K}$, the rate of bromine formation remains much higher compared with the upward cycle. Afterwards, the activity drops significantly at $473 \mathrm{~K}$ (Fig. 3, green triangles). The consecutive increase of the temperature is almost identical to the first temperature ramp, which indicates the absence of irreversible catalyst deactivation (Fig. 3, red diamonds). The hysteresis could be due to the uptake of bromine at low temperatures, which hampers the catalysts' activity. Once reaching to a certain temperature the bromine is released and the activity increases significantly (vide infra).

Lower temperatures could favor the uptake of chlorine leading to subsurface and bulk chlorination as shown before [9]. However, we cannot confirm if the uptake of chlorine would 
become equally large as observed in the case of bromine. In $\mathrm{HBr}$ oxidation, it is likely that higher temperatures could lead to a more constant behavior (i.e. no hysteresis) of the catalysts, since the oxidic phase is more stable than the bromide phase at higher temperatures, as reported elsewhere [28]. The fact that we observe the hysteresis in $\mathrm{HBr}$ and not in $\mathrm{HCl}$ oxidation at the light-off points of the catalysts under comparable conditions indicates that the impact of bromination on the activity of the catalysts is much more detrimental than the chlorination.

The oxygen partial pressure is another important parameter that has been shown to affect the activity and stability of ceria catalysts in $\mathrm{HCl}$ oxidation $[8,16]$. Herein, the $\mathrm{O}_{2}: \mathrm{HX}$ feed ratio was cycled over CZ75-h, CZ75-nh, and CZ100 (Figs. 4 and S3). The activity of the catalysts decreases with lower oxygen partial pressure. However, the cycling of the $\mathrm{O}_{2}: \mathrm{HCl}$ feed ratio does not show any effect on the activity of the catalysts (Fig. S3), because both temperature $(698 \mathrm{~K})$ and oxygen partial pressure $\left(\mathrm{O}_{2}: \mathrm{HCl}\right.$ between 2 and 0.75$)$ are high enough to balance the chlorination of the catalyst surface and subsurface $[8,16]$. In order to compare $\mathrm{HBr}$ and $\mathrm{HCl}$ oxidation at a similar activity level, the variation of the $\mathrm{O}_{2}: \mathrm{HBr}$ feed ratio was performed at $c a$. $523 \mathrm{~K}$, (Fig. 4). The catalysts activity is at 4.0 and $6.0 \mathrm{~mol} \mathrm{Br}_{2} \mathrm{~mol} \mathrm{Ce} \mathrm{h}^{-1}$ for CZ75-h and CZ75nh, respectively. The activity of CZ100 reaches $19 \mathrm{~mol} \mathrm{Br}_{2} \mathrm{~mol} \mathrm{Ce} \mathrm{h}^{-1}$ (Fig. 4, blue circle), which is significantly higher than during the temperature cycles in Fig. 3. The difference could be due to bromination of $\mathrm{CZ100}$ at $473 \mathrm{~K}$ in the temperature cycle experiment, reducing its activity significantly (Fig. 3, blue circle). Upon reduction of the $\mathrm{O}_{2}: \mathrm{HBr}$ feed ratio, a strong drop in activity is observed for all materials. In the consecutive upward cycle, the catalysts cannot regain their initial activity levels reaching only ca. $50 \%$ of the original bromine formation rate at $\mathrm{O}_{2}: \mathrm{HBr}=2$ (Fig. 4, green triangles). In the successive decease of the $\mathrm{O}_{2}: \mathrm{HBr}$ ratio (Fig. 4, red diamonds), the activity drops further, pointing to an irreversible deactivation of the catalysts under the applied conditions. This behavior could be due to the slow or inhibited desorption of bromine at this temperature $(523 \mathrm{~K})$ in combination with the low oxygen partial pressures. As shown in 
Fig. 3, the ceria-based catalysts experience a lower activity at $523 \mathrm{~K}$ after precedent bromination at low temperatures. This indicates that the temperature of $523 \mathrm{~K}$ is too low to enforce the removal of bromine from the surface and thus the catalyst cannot recover its activity when returning to a higher oxygen partial pressure $\left(\mathrm{O}_{2}: \mathrm{HBr}=2\right)$. Compared to $\mathrm{HCl}$ oxidation, the dependence of the ceria-zirconia catalyst on re-oxidation in $\mathrm{HBr}$ oxidation can be considered higher due to the strong bromination. Therefore, a high oxygen partial pressure and temperature is needed in order to facilitate oxygen- and temperature-assisted bromine removal.

A long-term test was conducted to further investigate the stability of CZ75-h and CZ75-nh (Fig. 5). The catalysts were tested at $533 \mathrm{~K}$ to ensure a higher stability against bromination compared to the cycling experiments. The rate of bromine formation over CZ75-h stabilizes within the first $35 \mathrm{~h}$ on stream at $7.4 \mathrm{~g} \mathrm{Br}_{2} \mathrm{~g}_{\mathrm{cat}}{ }^{-1} \mathrm{~h}^{-1}$. The activity of CZ75-nh does not stabilize and drops continuously reaching $2.2 \mathrm{~g} \mathrm{Br}_{2} \mathrm{~g}_{\mathrm{cat}}{ }^{-1} \mathrm{~h}^{-1}$ after $40 \mathrm{~h}$ on stream. This verifies that the homogeneous catalyst is more stable and active than its non-homogeneous counterpart.

\subsection{Characterization of the used catalysts}

After completing the $\mathrm{O}_{2}: \mathrm{HX}$ cycling experiment (Figs. 4 and S3), the ceria-zirconia catalysts were recovered and characterized to obtain insights into compositional and textural changes upon $\mathrm{HBr}$ and $\mathrm{HCl}$ oxidation. X-ray diffraction analysis of the used CZ75-h and CZ75-nh catalysts (Fig. 1a) shows that the exposure to $\mathrm{HCl}+\mathrm{O}_{2}$ reaction mixture does not alter the $\mathrm{XRD}$ patterns significantly. On the contrary, exposure to $\mathrm{HBr}$ results in the appearance of new XRD features in both CZ75-h and CZ75-nh. This effect is more pronounced on the nonhomogeneous sample, for which a strong decrease of the intensity of the main reflection is also recorded. Because of the formation of several types of $\mathrm{Ce}-\mathrm{Br}$ and $\mathrm{Zr}-\mathrm{Br}$ compounds, phase identification of the new XRD features is difficult and the peaks cannot be unequivocally attributed neither to the $\mathrm{CeBr}_{3}$ (JCPDS 75-1898) and $\mathrm{ZrBr}_{3}$ (JCPDS 26-1400) references, nor to 
oxybromide structures such as $\mathrm{ZrBrO}_{0.23}$ (JCPDS 76-1576). $\mathrm{HBr}$ and $\mathrm{HCl}$ oxidation also affect the total surface area of the samples. In fact, upon reaction, a decrease of surface area is observed in all catalysts. This drop is more drastic after $\mathrm{O}_{2}: \mathrm{HBr}$ variation in $\mathrm{HBr}$ oxidation, in line with the XRD data.

Microscopy evaluation reveals no compositional changes after $\mathrm{HCl}$ and $\mathrm{HBr}$ oxidation. On the other hand, the particle morphology and crystallinity of the non-homogeneous catalyst appear to be changed after $\mathrm{HBr}$ oxidation, showing large grains comprised of randomly-oriented nanocrystals. This sample also contains a much higher (stoichiometric) concentration of bromine. These results are in line with the decreased surface area and pore volume determined by $\mathrm{N}_{2}$ sorption. The micrographs in Fig. $\mathrm{S} 4$ after the long-term test also demonstrate that the homogeneous composite retains its morphology and crystallinity after the reaction. In contrast, the non-homogeneous sample is majorly transformed into grains of variable nanocrystals, which explains the difficulty to detect the crystalline phases by XRD. EDS analysis confirms the phaseseparation of Ce-rich and Zr-rich domains and reveals a near stoichiometric uptake of bromine to metal in this sample. Fig. $1 \mathrm{~b}$ depicts the $\mathrm{H}_{2}$-TPR profiles of $\mathrm{CZ75}$-h and $\mathrm{CZ75}$-nh after $\mathrm{HCl}$ and $\mathrm{HBr}$ oxidation. In general, the reactions alter the redox properties of the homogeneous and non-homogeneous catalysts to a different extent. In the non-homogeneous sample, the peak at $623 \mathrm{~K}$ disappears after reaction in $\mathrm{HBr}$ and $\mathrm{HCl}$ oxidation, while the peaks at $823 \mathrm{~K}$ and $1023 \mathrm{~K}$ are shifted to lower temperatures. Focusing on CZ75-h, the TPR profile is slightly affected by the presence of $\mathrm{HCl}+\mathrm{O}_{2}$ reaction mixture, and only a very slight shift of the maximum towards higher temperatures is detected. This shift is accompanied by a decrease in reducibility of about $20 \%$ (Table 1). On the other hand, upon $\mathrm{HBr}$ oxidation, the peak decreases in intensity as the reducibility drops by almost $40 \%$. This indicates the more favorable inhibition of the ceria reducibility by the bromine species, which is in agreement with the analysis of the effluent gas during the drying step before the TPR measurement, which indicates that the CZ75-h sample contained large amounts of water and bromine after reaction (Fig. S5) 


\subsection{Halogen uptake on ceria-zirconia catalysts}

As the characterization data have shown, the halogen uptake of the catalyst under reaction conditions is a key descriptor of its activity and stability. Operando PGAA has shown to be a reliable analytical technique to unequivocally determine the elemental and isotopic compositions of the samples $[9,16,24]$. The technique is based on the radiative neutron capture, or $(n, \gamma)$ reaction upon irradiation of the sample with cold neutrons (Fig. 6a). Directly after capturing a neutron, the nucleus returns to its ground state, by emitting typically 2 to 4 gamma rays in a cascade. The gamma radiation is characteristic, i.e. the energy values of the gamma rays identify the nuclide, and their intensities are proportional to the number of atoms present in the analyzed volume. Using a data base the count rate of the analytical peak can be related to the quantity of the element without using a standard [40]. The sensitivity and the detection limit of PGAA differ from element to element, and depend on the partial gamma-ray production crosssection, the detector efficiency and the level of the baseline at the analytical line. The dynamic range of the method is limited by either the too small sensitivity, such as oxygen, or by the too high counting rate that overloads the counting system, e.g. iridium.

A region of the PGAA spectrum for the CZ75-nh catalyst is shown in Fig. 6b. The spectrum contains more than hundred peaks which correspond to all elements that were in the path of neutrons including for example signals assigned to Si from the quartz reactor. The peaks of interest that belong to the most intense lines of $\mathrm{Cl}, \mathrm{Br}, \mathrm{Zr}$, and $\mathrm{Ce}$ were evaluated with a weighted nonlinear least square fit method to determine the peak areas and peak positions (Fig. 6c). As most elements have more than one peak, the internal consistency of the mass determination can be verified. The molar ratios $\mathrm{X}:(\mathrm{Ce}+\mathrm{Zr})$ were determined from the characteristic peak areas corrected by the detector efficiency at the given energy and the nuclear data of the observed elements (Fig. 6c). 
The halogen uptake for CZ75-h and CZ75-nh was determined under variable $\mathrm{O}_{2}: \mathrm{HX}$ feed conditions (Fig. 7). Due to the increased catalyst amount and the different experimental protocol concerning the order of the measurements the $\mathrm{HBr}$ and $\mathrm{HCl}$ conversion was higher than in the experiments shown in Section 3.2. At $\mathrm{O}_{2}: \mathrm{HBr}=4$, the uptake of bromine and the reaction rate of both catalysts are around $0.1 \mathrm{Br}:(\mathrm{Ce}+\mathrm{Zr})$ and $14.5 \mathrm{~mol} \mathrm{Br}_{2} \mathrm{~mol} \mathrm{Ce} \mathrm{h}^{-1}$, respectively. When decreasing the $\mathrm{O}_{2}: \mathrm{HBr}$ from 4 to 1 , the activity of both materials decreases by $70 \%$, while the bromine uptake increases to 0.25 for the homogeneous and $0.43 \mathrm{Br}$ : $(\mathrm{Ce}+\mathrm{Zr}$ ) for the nonhomogeneous catalyst at $\mathrm{O}_{2}: \mathrm{HBr}=1$ (Fig. 7a). In contrast to that, the chlorine uptake is significantly lower and does not change on both catalysts upon decreasing $\mathrm{O}_{2}: \mathrm{HCl}$ feed ratios from 9 to 1 (Fig. 7 b). However, halogenation is not only facilitated at lower oxygen partial pressure, but also occurs at low bed temperatures. When increasing the temperature from $473 \mathrm{~K}$ to $523 \mathrm{~K}$ over CZ75-h, the bromine uptake continues to increase (Fig. 8). As the temperature is set to $553 \mathrm{~K}$ (Fig. 8, A), the uptake is halved while the activity quadruples. When reducing the temperature again to $523 \mathrm{~K}$ (Fig. 8, B), the activity remains at a higher level and the halogen uptake stays low, which is in agreement with the hysteresis observed in Fig. 3. However, the activity drops further within an additional 2.5 hours on stream due to a continuous increase of the bromine uptake (Fig. 8, C). This indicates that the $\mathrm{Br}$ uptake at these conditions has not reached equilibrium, yet. The $\mathrm{Cl}$ uptake, on the other hand, is $50 \%$ lower than the $\mathrm{Br}$ uptake and decreases with higher bed temperature, which is in line with recent studies [9]. The strong impact of bromination suggests that a high $\mathrm{O}_{2}$ partial pressure and a temperature high enough to stay above the light-off point is required to operate a ceria-zirconia catalyst in $\mathrm{HBr}$ oxidation. This also suggests that in some cases it is possible to recover the loss of activity, which is caused by the uptake of bromine over time, through a thermal treatment. However, the drastic increase in activity in combination with the strong reduction of the bromine uptake above $523 \mathrm{~K}$ indicates that bromine evolution on ceria-based catalysts becomes possible only in a very narrow temperature range and strongly depends on the bromine uptake of the catalyst. 
The large uptake of bromine indicates that cerium oxide can brominate to cerium bromide at low temperatures and $\mathrm{O}_{2}: \mathrm{HBr}$ feed compositions. The latter can be oxidized to cerium oxide at $585 \mathrm{~K}$ [28] or hydrolyzed to $\mathrm{CeOBr}$ at $593 \mathrm{~K}$ [41]. Nevertheless the stability of $\mathrm{CeOBr}$ under $\mathrm{HBr}$ oxidation conditions remains unclear. In the case of $\mathrm{HCl}$ oxidation, it was indicated that the chlorination of cerium oxide could lead to the formation of chlorides and oxychlorides under reaction conditions [42]. However, only the formation of cerium chloride hydrate using ex situ characterization techniques was proven $[8,9]$. Testing cerium oxychloride $(\mathrm{CeOCl})$ in $\mathrm{HCl}$ oxidation has shown that this compound is highly unstable leading to its decomposition to $\mathrm{CeO}_{2}$ under $\mathrm{O}_{2}$-rich conditions [43]. It seems plausible that cerium oxychloride and oxybromide compounds decompose to metal oxides under the reaction conditions.

Furthermore, the observed strong structural changes and the detected large bromine uptake seem affect the activity of the catalysts significantly; explaining the higher activity of the nonhomogeneous material compared to the homogeneous catalyst during the cycling experiments in Fig. 3 and 4. It is possible that the non-homogeneous sample utilizes more bulk $\mathrm{CeO}_{2}$ in the reaction by consuming its lattice oxygen to a higher extent than the homogeneous sample. Thus, the formation of cerium bromide species and their subsequent decomposition or reoxidation might lead to a higher activity of the non-homogeneous sample compared to the homogeneous material (Fig. 3). A similar effect has been observed during tests on $\mathrm{CeBr}_{3}$ in $\mathrm{HBr}$ oxidation, where the activity increased as the $\mathrm{CeBr}_{3}$ oxidized to $\mathrm{CeO}_{2}$ under comparable experimental conditions [28]. This, however, only exists temporarily as the increasing bromine uptake leads to lower stability of the catalyst and ultimately to lower or no activity of the material, as shown in the long-term test (Fig. 5). Compared to the non-homogeneous catalyst, pure ceria exhibits a more dynamic character with respect to the formation and decomposition of cerium bromide (Fig. 4). This leads to stronger differences in activity depending on the sample history and reactions conditions. 


\subsection{Impact of the Ce:Zr ratio on the halogen uptake}

In order to assess the influence of the composition of the homogeneous ceria-zirconia mixed oxide on the catalytic performance, $\mathrm{CeO}_{2}-\mathrm{ZrO}_{2}$ mixed oxides with variable $\mathrm{Zr}$ content $(0,25,50$, 90, and $100 \mathrm{~mol} . \% \mathrm{Zr}$ ) were tested in $\mathrm{HCl}$ and $\mathrm{HBr}$ oxidation under harsh conditions $\left(\mathrm{O}_{2}: \mathrm{HX}=0.75\right)$. The formation of maxima can be understood as a compromise between the increasing intrinsic activity of the catalysts and the increasing halogen uptake at lower $\mathrm{Zr}$ content, as $\mathrm{ZrO}_{2}(\mathrm{CZO})$ itself is inactive in both reactions (Fig. 9a). These maxima mark the optimal $\mathrm{Zr}$ content for the ceria-zirconia in both $\mathrm{HBr}$ and $\mathrm{HCl}$ oxidation between ca. 90 and 70 mol.\% Zr, which coincides with the minimization of the halogen content (Fig. 9b). The bromine content of $\mathrm{CZ100}$ is 30 at. $\% \mathrm{Br}$, while the chlorine content is only 7 at. $\% \mathrm{Cl}$ according to the elemental analysis. When increasing the $\mathrm{Zr}$ content the halogen content in CZ10-h drops to 3 at. $\% \mathrm{Br}$ and 2 at. $\% \mathrm{Cl}$, respectively. Due to the higher $\mathrm{Br}$ content compared to $\mathrm{Cl}$, the optimum for $\mathrm{HBr}$ oxidation seems to have further shifted towards a higher $\mathrm{Zr}$ content. Therefore, halogen uptake can be controlled by tuning the Ce:Zr ratio of the catalysts, which is in line with recent work on $\mathrm{HCl}$ oxidation [26]. A similar effect has also been observed in the literature with regard to the thermal robustness of the ceria-zirconia catalysts, where Zr-rich materials are generally recommended for high-temperature applications in TWC due to their better resistance against sintering [37].

\section{Conclusions}

We have prepared ceria-zirconia catalysts with homogeneous and non-homogeneous metal distribution and different $\mathrm{Ce}: \mathrm{Zr}$ ratios, determining the impact of zirconia on ceria in $\mathrm{HBr}$ and $\mathrm{HCl}$ oxidation. The incorporation of $25 \mathrm{~mol} . \% \mathrm{Zr}$ promotes the activity and stability of ceria in both reactions, independently of the degree of intermixing of the ceria and zirconia phases. Upon cycling of temperature and $\mathrm{O}_{2}: \mathrm{HX}$ ratio, no differences in the activity trends are observed in $\mathrm{HCl}$ oxidation. However, the cycling in $\mathrm{HBr}$ oxidation results in a hysteresis due to the bromination of 
the materials. The characterization of the catalysts after reaction by HRTEM and XRD confirms this result, showing the presence of bromide species on the surface and in the bulk of the catalyst. The homogeneous mixed oxide incorporates less bromide species compared to its non-homogeneous counterpart, exhibiting a better structural resistance and showing a more stable behavior in $\mathrm{HBr}$ oxidation during a test for $40 \mathrm{~h}$ on stream. The halogenation of the catalysts during reaction was further analyzed using operando PGAA. In $\mathrm{HCl}$ oxidation, we observe no impact of the phase homogeneity of the material on the chlorine uptake. However, the $\mathrm{HBr}$ oxidation rate depends strongly on the bromine uptake, and the non-homogeneous sample experiences an almost $50 \%$ higher bromine uptake than the homogeneous material when lowering the $\mathrm{O}_{2}: \mathrm{HBr}$ feed ratio. These results indicate that a homogeneous intermixing of the ceria and zirconia phase is essential to minimize structural changes. The comparison of homogeneous ceria-zirconia catalysts with different $\mathrm{Ce}: \mathrm{Zr}$ ratios points out that the halogen uptake could be minimized by tuning the Ce:Zr ratio of the catalyst. In particular, the optimal $\mathrm{Zr}$ content is observed between 70 and 90 mol.\% Zr. Since ceria-zirconia catalysts under equal reaction rates are more prone to brominate than chlorinate, the supported ceria catalyst design applied in $\mathrm{HCl}$ oxidation cannot be directly extrapolated to $\mathrm{HBr}$ oxidation. Well-mixed ceriazirconia mixed oxide can be considered the desirable active phase due to their higher resistance to bromination, rendering them more efficient than supported catalysts since the homogeneous metal distribution is very difficult to ensure in the latter case.

Acknowledgements. We thank Dr. Roland Hauert for conducting XPS analysis, and Dr. Zhen Guo and Vladimir Paunović for technical assistance during operando PGAA experiments. The European Union's $7^{\text {th }}$ Framework Programme (NMI3-II Grant number: 283883) is thanked for funding the PGAA experiments at the Budapest Neutron Centre. ScopeM (ETH Zurich) is acknowledged for providing its microscopy facilities. 
Supplementary material. Supplementary data associated with this article, containing additional characterization and catalytic data, can be found in the online version.

\section{References}

[1] A. Trovarelli, C. de Leitenburg, M. Boaro, G. Dolcetti, Catal. Today 50 (1999) 353.

[2] Y. Madier, C. Descorme, A.M. Le Govic, D. Duprez, J. Phys. Chem. B 103 (1999) 10999.

[3] Q. Fu, H. Saltsburg, M. Flytzani-Stephanopoulos, Science 301 (2003) 935.

[4] Z. Shao, S.M. Haile, Nature 431 (2004) 170.

[5] O. Pozdnyakova, D. Teschner, A. Wootsch, J. Kröhnert, B. Steinhauer, H. Sauer, L. Toth, F.C. Jentoft, A. Knop-Gericke, Z. Paál, R. Schlögl, J. Catal. 237 (2006) 1.

[6] G. Vilé, B. Bridier, J. Wichert, J. Pérez-Ramírez, Angew. Chem., Int. Ed. 51 (2012) 8620.

[7] J. Pérez-Ramírez, C. Mondelli, T. Schmidt, O.F.-K. Schlüter, A. Wolf, L. Mleczko, T. Dreier, Energy Environ. Sci. 4 (2011) 4786.

[8] A.P. Amrute, C. Mondelli, M. Moser, G. Novell-Leruth, N. Lopez, D. Rosenthal, R. Farra, M.E. Schuster, D. Teschner, T. Schmidt, J. Pérez-Ramírez, J. Catal. 286 (2012) 287.

[9] R. Farra, M. Eichelbaum, R. Schlögl, L. Szentmiklósi, T. Schmidt, A.P. Amrute, C. Mondelli, J. Pérez-Ramírez, D. Teschner, J. Catal. 297 (2013) 119.

[10] S. Park, J.M. Vohs, R.J. Gorte, Nature 404 (2000) 265.

[11] C.T. Campbell, C.H.F. Peden, Science 309 (2005) 713.

[12] D.R. Mullins, Surf. Sci. Rep. 70 (2015) 42.

[13] F. Esch, S. Fabris, L. Zhou, T. Montini, C. Africh, P. Fornasiero, G. Comelli, R. Rosei, Science 309 (2005) 752.

[14] M. V. Ganduglia-Pirovano, J.L.F. Da Silva, J. Sauer, Phys. Rev. Lett. 102 (2009) 026101. 
[15] J.-F. Jerratsch, X. Shao, N. Nilius, H.-J. Freund, J. Sauer, Phys. Rev. Lett. 106 (2011) 246801.

[16] M. Moser, C. Mondelli, T. Schmidt, F. Girgsdies, M.E. Schuster, R. Farra, L. Szentmiklósi, D. Teschner, J. Pérez-Ramírez, Appl. Catal., B 132-133 (2013) 123.

[17] A. Trovarelli, Catal. Rev. 38 (1996) 439.

[18] A. Trovarelli, M. Boaro, E. Rocchini, C. de Leitenburg, G. Dolcetti J. Alloys Compd. 323 (2001) 584 .

[19] E.W. McFarland, H. Metiu, Chem. Rev. 113 (2013) 4391.

[20] G. Vilé, P. Dähler, J. Vecchietti, M. Baltanás, S. Collins, M. Calatayud, A. Bonivardi, J. Pérez-Ramírez, J. Catal. 324 (2015) 69.

[21] J. Kašpar, P. Fornasiero, N. Hickey, Catal. Today 77 (2003) 419.

[22] B.M. Reddy, P. Bharali, P. Saikia, A. Khan, S. Loridant, M. Muhler, W. Grünert, J. Phys. Chem. C 111 (2007) 1878.

[23] R.J. Gorte, AICHE J. 56 (2010) 1126.

[24] R. Farra, M. García-Melchor, M. Eichelbaum, M. Hashagen, W. Frandsen, J. Allan, F Girgsdies, L Szentmiklósi, N. López, D. Teschner, ACS Catal. 3 (2013) 2256.

[25] C.H. Kanzler, S. Urban, K. Zalewska-Wierzbicka, F. Hess, S. F. Rohrlack, C. Wessel, R. Ostermann, J.P. Hofmann, B.M. Smarsly, H. Over, ChemCatChem 5 (2013) 2621.

[26] M. Möller, H. Over, B. Smarsly, N. Tarabanko, S. Urban, Catal. Today (2015) doi:10.1016/j.cattod.2015.02.027.

[27] E. McFarland, Science 338 (2012) 340.

[28] M. Moser, L. Rodríguez-García, A.P. Amrute, J. Pérez-Ramírez, ChemCatChem 5 (2013) 3520.

[29] M. Moser, I. Czekaj, N. López, J. Pérez-Ramírez, Angew. Chem. Int. Ed. 53 (2014) 8628.

[30] A. Pappacena, P. Porreca, M. Boaro, C. de Leitenburg, A. Trovarelli, Int. J. Hydrogen Energy 37 (2012) 1698. 
[31] A. Pappacena, K. Schermanz, A. Sagar, E. Aneggi, A. Trovarelli, Stud. Surf. Sci. Catal. $175(2010) 835$.

[32] A.C. Larson, R.B. Von Dreele General Structure Analysis System (GSAS), Los Alamos National Laboratory Report LAUR, 2000, p. 86.

[33] A.P. Amrute, C. Mondelli, M. A. G. Hevia , J. Pérez-Ramírez, J. Phys. Chem. C, 115 (2011) 1056.

[34] L. Szentmiklósi, T. Belgya, Z. Révay, Z. Kis, J. Nucl. Radioanal. Chem. 286 (2010) 501.

[35] D. Teschner, J. Borsodi, A. Wootsch, Z. Révay, M. Hävecker, A. Knop-Gericke, S.D. Jackson, R. Schlögl, Science 320 (2008) 86.

[36] D. Teschner, G. Novell-Leruth, R. Farra, A. Knop-Gericke, R. Schlögl, L. Szentmiklósi, M.G. Hevia, H. Soerijanto, R. Schomäcker, J. Pérez-Ramírez, N. López, Nat. Chem. 4 (2012) 739.

[37] J. Kašpar, P. Fornasiero, G. Balducci, R. Di Monte, N. Hickey, V. Sergo, Inorg. Chim. Acta 349 (2003) 217.

[38] E. Aneggi, C. de Leitenburg, A. Trovarelli, Catal. Today 181 (2012) 108.

[39] G. Vilé, S. Colussi, F. Krumeich, A. Trovarelli, J. Pérez-Ramírez, Angew. Chem., Int. Ed. $53(2014) 12069$.

[40] Z. Révay, Anal. Chem. 81 (2009) 6851.

[41] H. Chen, C. Zhou, P. Yang, J. Wang, J. Mater. Sci. Technol. 25 (2009) 753.

[42] H. Over, R. Schomäcker, ACS Catal. 3 (2013) 1034.

[43] R. Farra, F. Girgsdies, W. Frandsen, M. Hashagen, R. Schlögl, D. Teschner, Catal. Lett. 143 (2013) 1012. 
Table 1. Characterization data of the samples.

\begin{tabular}{|c|c|c|c|c|c|c|c|}
\hline \multirow{2}{*}{ Formula } & \multirow{2}{*}{ Sample } & \multirow{2}{*}{ Treatment } & \multicolumn{2}{|c|}{$\begin{array}{l}\text { Ce: }(\mathrm{Ce}+\mathrm{Zr}) \\
\left(\mathrm{mol} \mathrm{mol}{ }^{-1}\right)\end{array}$} & \multirow{2}{*}{$\begin{array}{c}S_{B E T^{c}} \\
\left(m^{2} g^{-1}\right)\end{array}$} & \multirow{2}{*}{$\begin{array}{c}V_{\text {pore }}{ }^{\mathrm{d}} \\
\left(\mathrm{cm}^{3} \mathrm{~g}^{-1}\right)\end{array}$} & \multirow{2}{*}{$\begin{array}{c}\mathrm{H}_{2} \text { consumption } \\
\left(\mathrm{mmol} \mathrm{g}^{-1}\right)\end{array}$} \\
\hline & & & Bulk $^{a}$ & Surface $^{b}$ & & & \\
\hline $\mathrm{CeO}_{2}$ & CZ100 & as-prepared & 1.00 & - & 49 & 0.18 & 1.15 \\
\hline \multirow[t]{3}{*}{$\mathrm{Ce}_{75} \mathrm{Zr}_{25} \mathrm{O}_{2}$} & CZ75-nh & as-prepared & 0.75 & 0.83 & 67 & 0.37 & 1.01 \\
\hline & & $\mathrm{HBr}$ oxidation & 0.75 & 0.77 & 16 & 0.06 & 0.66 \\
\hline & & $\mathrm{HCl}$ oxidation & 0.75 & 0.85 & 54 & 0.21 & 1.23 \\
\hline \multirow[t]{3}{*}{$\mathrm{Ce}_{75} \mathrm{Zr}_{25} \mathrm{O}_{2}$} & CZ75-h & as-prepared & 0.75 & 0.76 & 64 & 0.30 & 1.67 \\
\hline & & $\mathrm{HBr}$ oxidation & 0.75 & 0.72 & 17 & 0.16 & 1.06 \\
\hline & & $\mathrm{HCl}$ oxidation & 0.75 & 0.77 & 48 & 0.17 & 1.32 \\
\hline $\mathrm{Ce}_{50} \mathrm{Zr}_{50} \mathrm{O}_{2}$ & CZ50-h & as-prepared & 0.50 & - & 78 & 0.22 & 1.01 \\
\hline $\mathrm{Ce}_{10} \mathrm{Zr}_{90} \mathrm{O}_{2}$ & CZ10-h & as-prepared & 0.10 & - & 63 & 0.16 & 0.31 \\
\hline $\mathrm{ZrO}_{2}$ & CZO & as-prepared & 0.00 & - & 66 & 0.18 & - \\
\hline
\end{tabular}

${ }^{\mathrm{a}}$ XRF. ${ }^{\mathrm{b}}$ XPS. ${ }^{\mathrm{c}} \mathrm{BET}$ model. ${ }^{\mathrm{d}}$ Volume of $\mathrm{N}_{2}$ at $p / p_{0}=0.98 .{ }^{\mathrm{e}} \mathrm{H}_{2}$-TPR. 
Table 2. Structural analysis of the as-prepared samples.

\begin{tabular}{llcccc}
\hline \multirow{2}{*}{ Sample } & \multirow{2}{*}{ Phase } & \multirow{2}{*}{$\begin{array}{c}\text { Particle size } \\
(\mathrm{nm})\end{array}$} & \multicolumn{4}{c}{$\begin{array}{c}\text { Cell parameter } \\
(\AA)\end{array}$} \\
\cline { 4 - 6 } & & 14 & $5.4107(1)$ & - & $c$ \\
\hline CZ100 & cubic & 9 & $5.4031(4)$ & - & - \\
CZ75-nh & cubic $^{\mathrm{b}}$ & 6 & $5.3540(4)$ & - & - \\
CZ75-h & cubic & 5 & - & $3.7205(7)$ & $5.3574(9)$ \\
CZ50-h & tetragonal & 5 & - & $3.6200(6$ & $5.2048(9)$ \\
CZ10-h & tetragonal & 10 & - & $3.5962(2)$ & $5.1655(3)$ \\
CZ0 & tetragonal & 18 & $-b^{\prime}$ & - \\
\hline
\end{tabular}

${ }^{a}$ Scherrer equation. ${ }^{b}$ Segregation of tetragonal $\mathrm{ZrO}_{2}$ (ca. $10 \%$ ) is observed. 


\section{Figure captions}

Fig. 1. X-ray diffraction patterns (a) and temperature-programmed reduction in $\mathrm{H}_{2}$ (b) of the asprepared $\mathrm{CZ75}$ samples and after use in $\mathrm{HBr}$ and $\mathrm{HCl}$ oxidation. The molecular representations in the middle depict the surface state of the as-prepared CZ75-nh and CZ75-h catalysts. The reaction conditions are specified in the text. Phases: (- $) \mathrm{CeO}_{2}($ JCPDS 43-1002), ( $\mathbf{\nabla}) \mathrm{ZrO}_{2}$ (JCPDS 73-1441), and (•) $\mathrm{CeZrO}_{x}$ (JCPDS 28-0271, 38-1436, and 88-2395). The reference line at $28^{\circ} 2 \theta$ helps to better visualize the shift of the $\mathrm{CeO}_{2}(111)$ peak in the samples.

Fig. 2. High-resolution transmission electron microscopy of the as-prepared CZ75-nh (top) and CZ75-h (bottom) samples, after use in $\mathrm{HBr}$, and $\mathrm{HCl}$ oxidation. The reaction conditions are specified in the text. The insets show the energy-dispersive X-ray spectrometry maps of the same catalysts. The scale bar in the bottom image applies to all micrographs. Color codes: $\mathrm{Ce}$ in red, $\mathrm{Zr}$ in blue, and $\mathrm{Br}$ in green.

Fig. 3. Rate of halogen production over CZ75-h (a), CZ75-nh (b), and CZ100 (c) versus temperature at $\mathrm{O}_{2}: \mathrm{HX}=2$. The temperature cycles start at $473 \mathrm{~K}$ for $\mathrm{HBr}$ oxidation and at $648 \mathrm{~K}$ for $\mathrm{HCl}$ oxidation.

Fig. 4. Rate of bromine production versus $\mathrm{O}_{2}: \mathrm{HBr}$ feed ratio at $523 \mathrm{~K}$ over CZ75-h (a), CZ75-nh (b), and CZ100 (c). The cycles start at $\mathrm{O}_{2}: \mathrm{HBr}=2$.

Fig. 5. Space time yield versus time-on-stream over CZ75-h (blue) and CZ75-nh (red) at $533 \mathrm{~K}$ and $\mathrm{O}_{2}: \mathrm{HBr}=2$. 
Fig. 6. Illustration of the irradiation of a catalyst bed in a continuous-flow tubular reactor with a neutron beam leading to the emission of gamma radiation from the target nucleus (a). The position of the target elements are highlighted in this region of the PGAA spectrum (counts per second versus energy), which was acquired during the experiments over a ceria-zirconia catalyst (b). Evaluation and fitting of the signals matching to the target elements $\mathrm{Ce}, \mathrm{Zr}, \mathrm{Br}$, and $\mathrm{Cl}$. The energy level and the integrated area of the peaks are characteristic for each element and its quantity in the sample, respectively (c).

Fig. 7. Rate of halogen production during $\mathrm{HBr}(\mathrm{a})$ and $\mathrm{HCl}$ (b) oxidation versus the halogen uptake measured by operando prompt-gamma activation analysis over CZ75-h (blue) and CZ75-nh (red) at different feed $\mathrm{O}_{2}: \mathrm{HX}$ ratios. The temperature was set to $523 \mathrm{~K}$ and $698 \mathrm{~K}$ for $\mathrm{HBr}$ and $\mathrm{HCl}$ oxidation, respectively. The insets depict the surface halogenation over the catalysts. Color codes: $\mathrm{Ce}$ in red, $\mathrm{Zr}$ in blue, $\mathrm{O}$ in pale yellow, and $\mathrm{Br}$ or $\mathrm{Cl}$ in green.

Fig. 8. Rate of halogen formation during $\mathrm{HBr}$ (blue) and $\mathrm{HCl}$ (red) oxidation versus halogen uptake measured by operando prompt-gamma activation analysis over CZ75-h. In $\mathrm{HCl}$ oxidation, the temperature was increased from 648 to $723 \mathrm{~K}$. In $\mathrm{HBr}$ oxidation, the temperature was increased from 473 to $553 \mathrm{~K}(\mathrm{~A})$ and then decreased to $523 \mathrm{~K}(\mathrm{~B})$. At this condition, the change in activity was recorded after equilibration for $2.5 \mathrm{~h}(\mathrm{C})$.

Fig. 9. Rate of bromine (circles) and chlorine (squares) production versus cerium content in the homogeneous ceria-zirconia catalysts at $\mathrm{O}_{2}: \mathrm{HX}=0.75$. The temperature was set to $523 \mathrm{~K}$ and $698 \mathrm{~K}$ for $\mathrm{HBr}$ and $\mathrm{HCl}$ oxidation, respectively (a). Bromine (circles) and chlorine (squares) content versus cerium content of the homogeneous catalysts determined by elemental analysis after the reaction (b). 


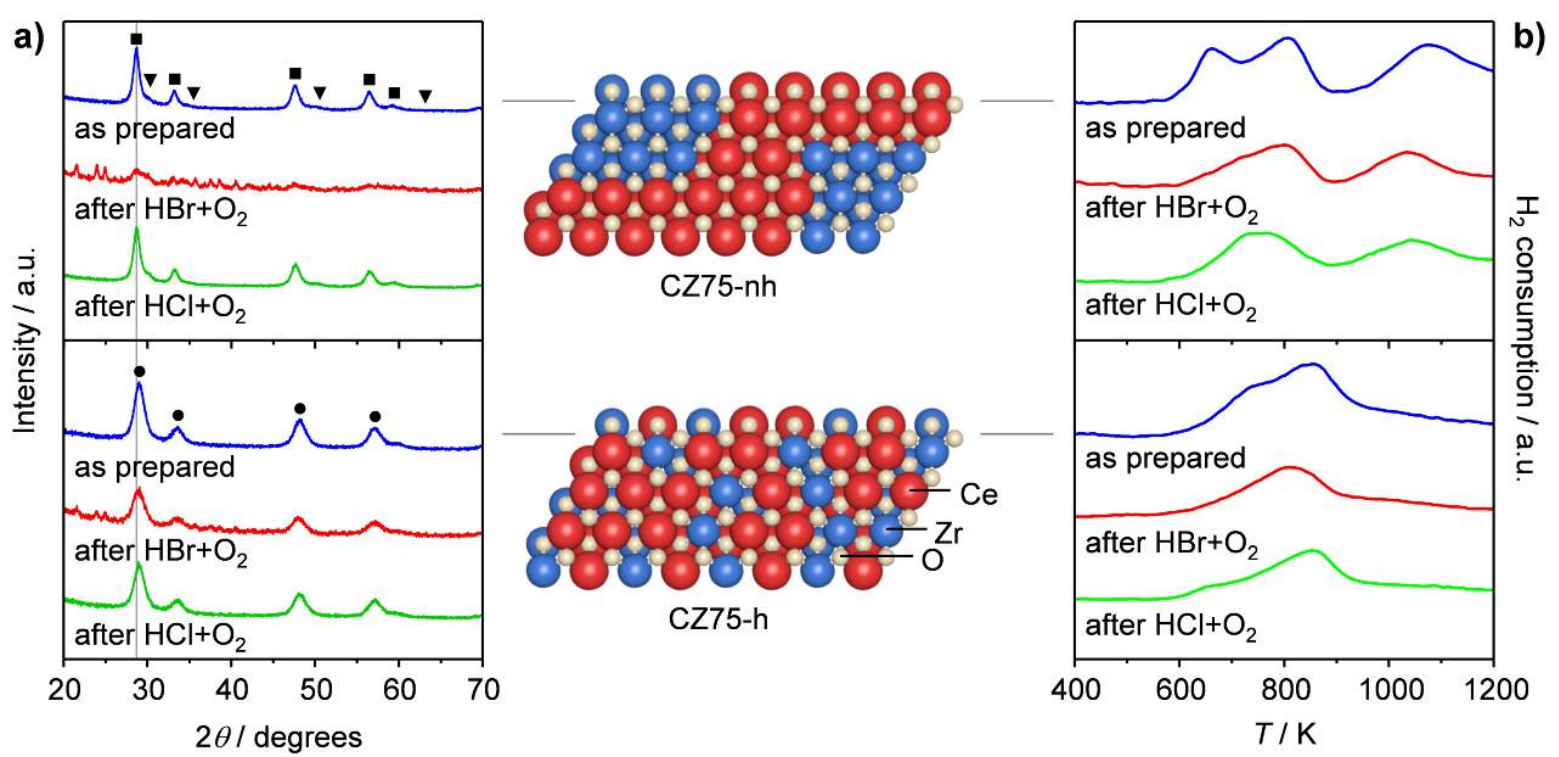

Fig. 1 
as-prepared
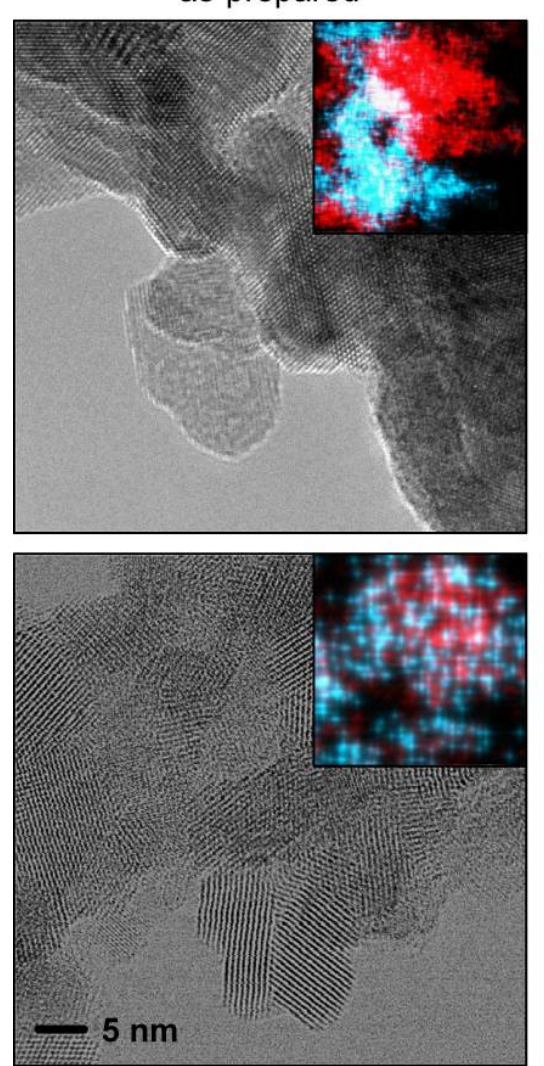

after $\mathrm{HBr}+\mathrm{O}_{2}$
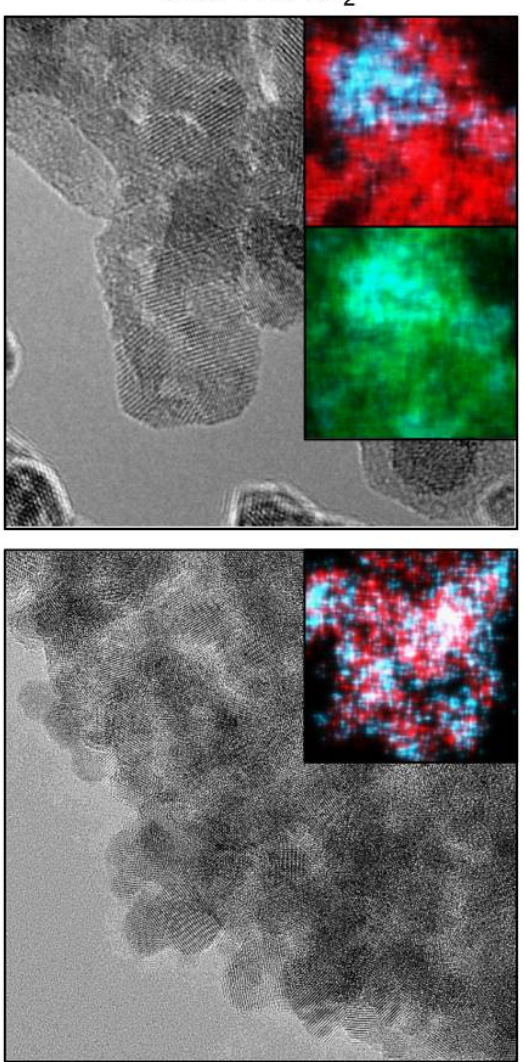

after $\mathrm{HCl}+\mathrm{O}_{2}$
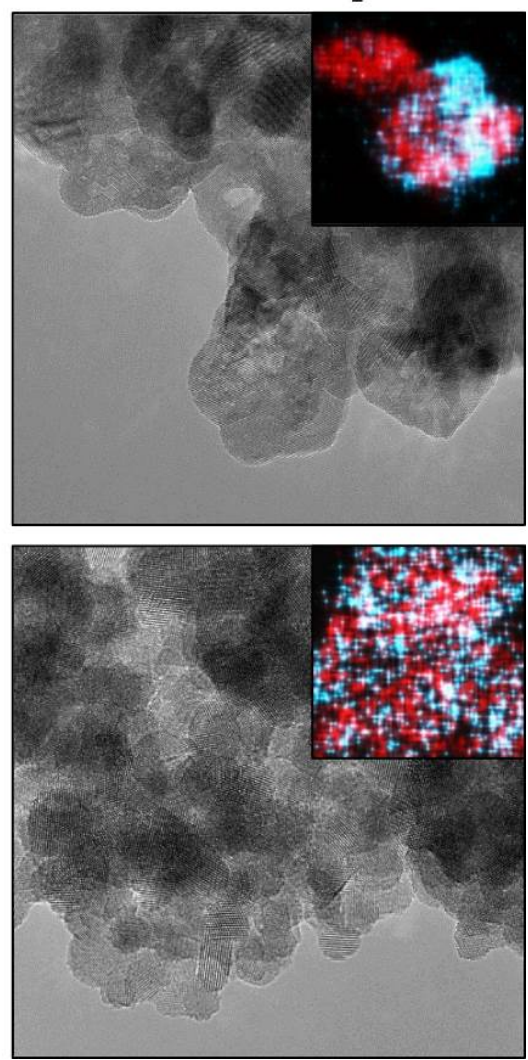

Fig. 2 

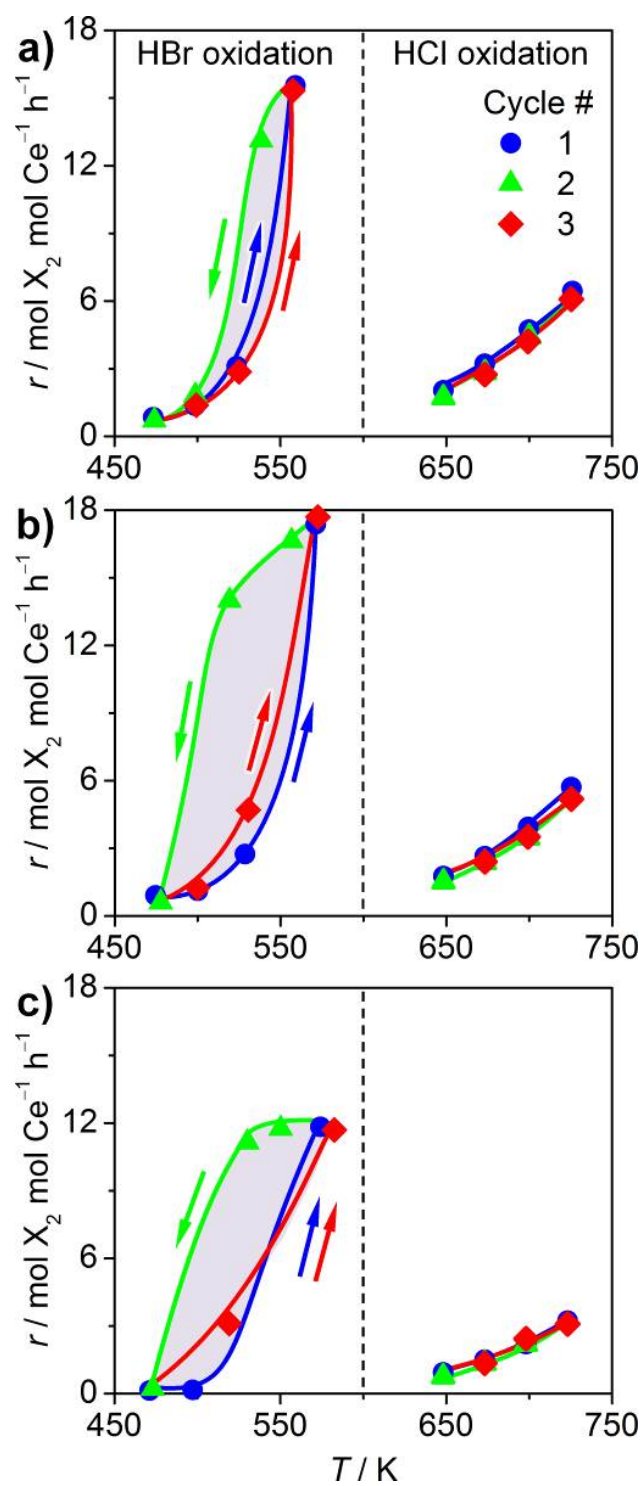

Fig. 3 
a) ${ }^{5}$. Cycle \#
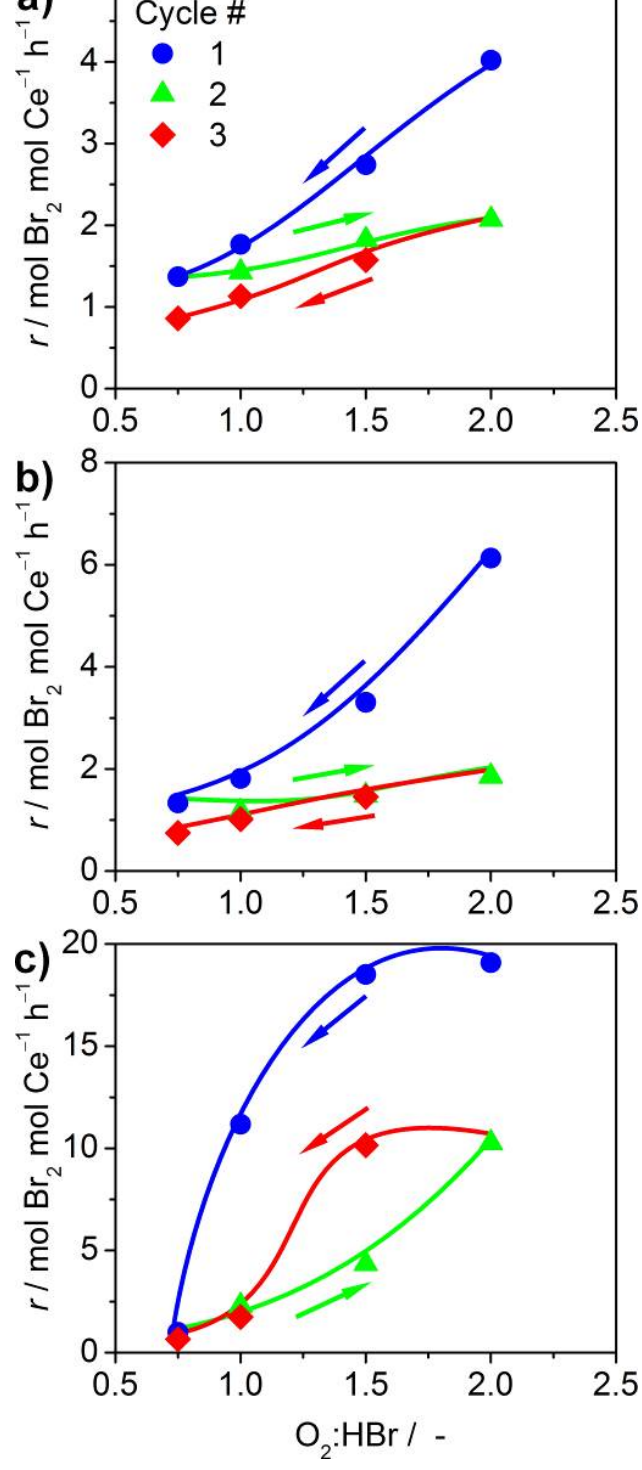

Fig. 4 


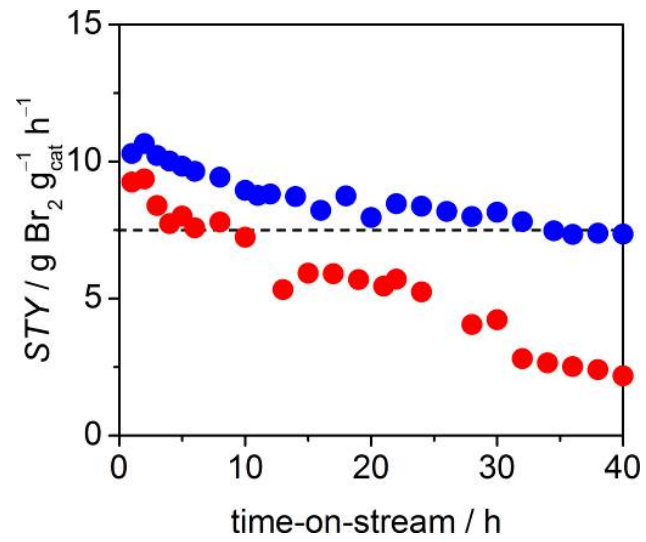

Fig. 5 
a)

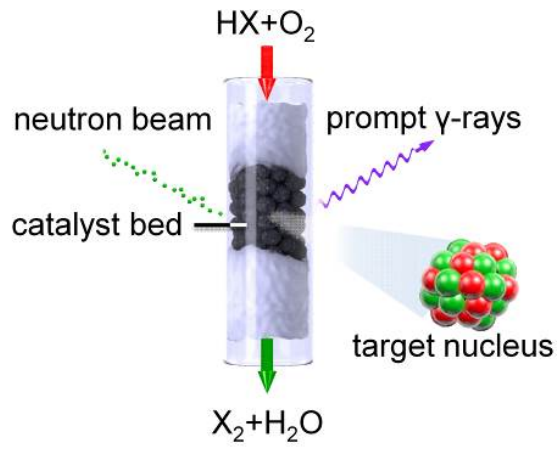

b)
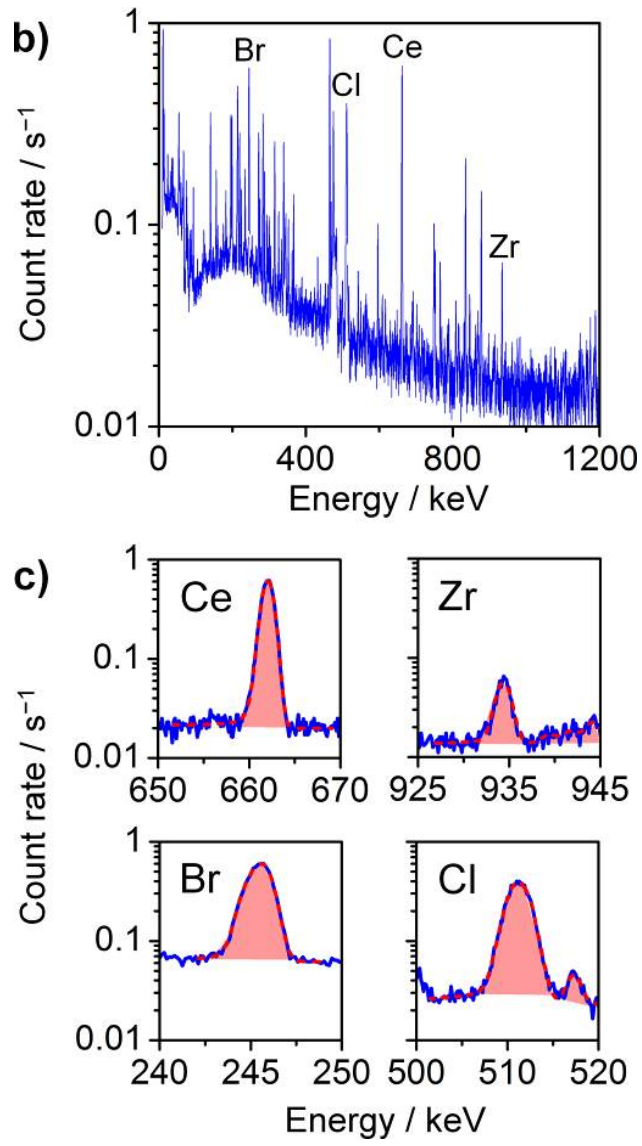

Fig. 6 

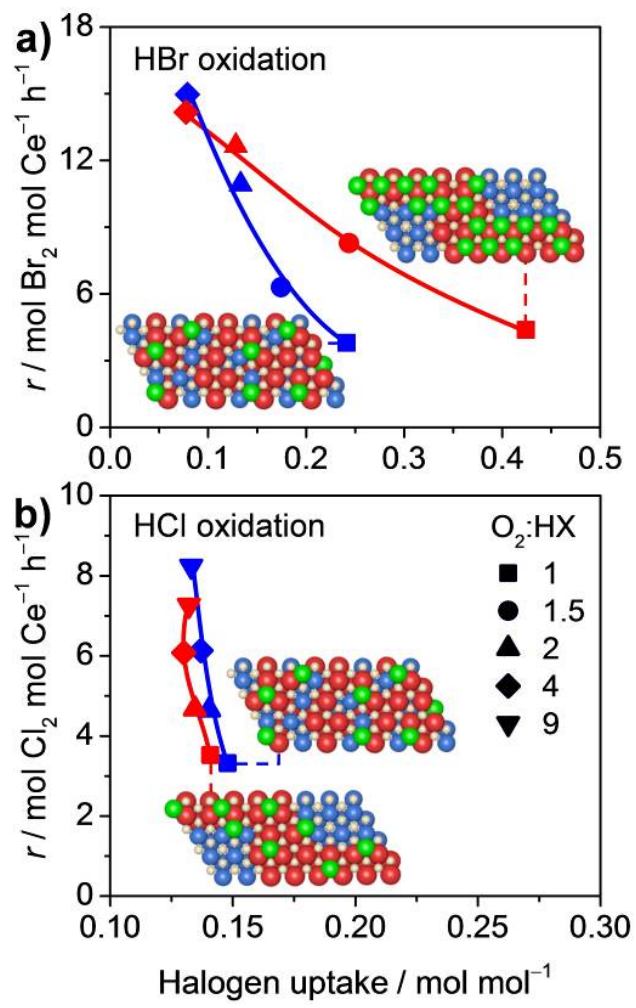

Fig. 7 


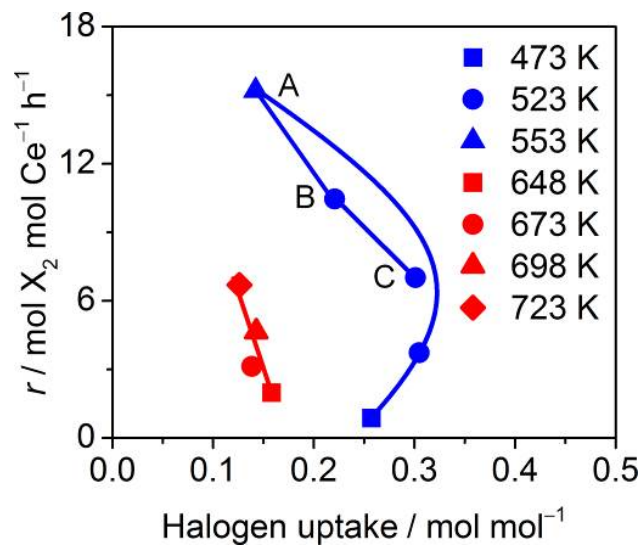

Fig. 8 

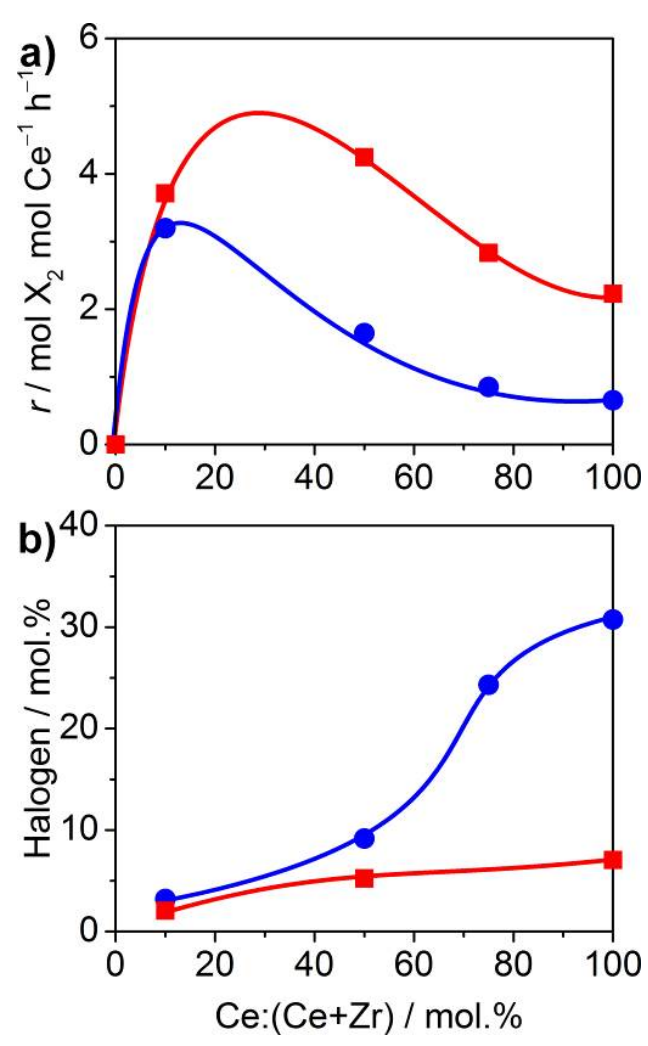

Fig. 9 